\title{
Kombinasi Single Linkage Dengan K-Means Clustering Untuk Pengelompokan Wilayah Desa Kabupaten Pemalang
}

\section{Combination Single Linkage With K-Means Clustering For Grouping Village Areas Of Pemalang District}

\author{
Sintiya ${ }^{1}$, Tri Ginanjar Laksana ${ }^{2}$, Nia Annisa Ferani Tanjung ${ }^{3}$ \\ 1,2,3 Teknik Informatika, Fakultas Informatika,Institut Teknologi Telkom Purwokerto \\ 17102141@ittelkom-pwt.ac.id ${ }^{1}$,anjarlaksana@ittelkom-pwt.ac.id ${ }^{2}$, nia@ittelkom-pwt.ac.id ${ }^{3}$
}

\begin{abstract}
Abstrak
Metode K-Means sangat bergantung pada penentuan pusat cluster awal yang berdampak pada kualitas cluster yang dihasilkan, selain penentuan pusat cluster jumlah $\mathrm{k}$ yang akan digunakan juga dapat mempengaruhi kualitas cluster dari metode K-Means. Kemiskinan sebagian besar dialami oleh masyarakat pedesaan, hal ini dapat dilihat dari masih rendahnya fasilitas yang ada untuk melayani kepentingan masyarakat dalam berbagai bidang. Untuk menghindari ketimpangan yang terjadi diperlukan suatu rencana pembangunan yang sesuai dengan karakteristik kesejahteraan masyarakat diwilayah tersebut. Oleh karena itu, diperlukan sebuah upaya pengelompokan desa agar pengambilan kebijakan menjadi tepat sasaran. Salah satu algoritma clustering yang umum digunakan adalah algoritma K-Means karena cukup sederhana, mudah diimplementasikan, dan memiliki kemampuan untuk mengelompokkan data yang besar dengan sangat cepat. Namun algoritma K-Means memiliki kelemahan pada penentuan pusat cluster awal yang diberikan. Inisialisasi pusat cluster secara acak dapat memberikan hasil pembentukan cluster yang berubahubah (tidak konsisten). Untuk itu, metode $K$-Means perlu dikombinasikan dengan metode hirarki dalam penentuan pusat cluster awal. Metode kombinasi ini disebut sebagai Hierarchical K-Means yang merupakan penggabungan antara metode hierarchical dan partitioning, di mana proses hierarchical digunakan untuk mencari inisialisasi pusat cluster awal dan proses partitioning untuk mendapatkan cluster yang optimal. Metode hirarki yang digunakan pada penelitian ini adalah metode single linkage. Berdasarkan metode Elbow jumlah k yang direkomendasikan untuk penelitian ini yaitu k $=4$. Kombinasi algoritma single linkage dan $k$-means dengan $\mathrm{k}=4$ pada penelitian ini menghasilkan nilai silhouette coefficient sebesar 0.685 yang merupakan kategori klaster yang layak atau sesuai, sedangkan pengukuran evaluasi dengan Davies Boulldin Index menghasilkan nilai 0.577.
\end{abstract}

Kata Kunci: Cluster, Davies Boulldin Index, K-means ,Silhouette coefficient,Single linkage

\begin{abstract}
K-Means is very dependent on determining the center cluster initial which has an impact on the quality of clusters resulting, in addition to determining the center of cluster the number of $\mathrm{k}$ that will be used it can also affect the quality of the cluster from the method $K$-Means. Poverty is mostly experienced by rural communities, this can be seen from the lack of existing facilities to serve the interests of the community in various fields. To avoid the imbalance that occurs, a development plan is needed in accordance with the characteristics of the welfare of the people in the region. Therefore, we need an effort to group villages so that policy making is right on target. One of the algorithms clustering that is commonly used is the K-Means algorithm because it is quite simple, easy to implement, and has the ability to group large data groups very quickly. However, the K-Means algorithm has a weakness in determining the center cluster initial given. Initialization of centers cluster randomly may result in formation clusters changing (inconsistent). For this reason, the $K$-Means method needs to be combined with the hierarchical method in determining the center cluster initial. This combination method is called Hierarchical K-Means which is a combination of methods hierarchical and partitioning, where the process is hierarchical used to find the initial center initialization cluster and the process partitioning to get the cluster optimal. The hierarchical method used in this study is the method single linkage. Based on the method Elbow, the recommended amount of $\mathrm{k}$ for this study is $\mathrm{k}=4$. The combination of the single linkage and $k$-means algorithms with $\mathrm{k}=4$ in this study results in avalue silhouette coefficient of 0.685 which is a feasible or appropriate cluster category, while the evaluation measurement by Davies The Boulldin Index yielded a value of 0.577 .
\end{abstract}

Keywords: Cluster, Davies Boulldin Index, K-means ,Silhouette coefficient,Single linkage , Prediction 


\section{Pendahuluan}

Kabupaten Pemalang merupakan kabupaten yang luas wilayahnya mencapai $1.115,30 \mathrm{~km}^{2}$. Berdasarkan letak administratif, Kabupaten Pemalang terdiri atas 14 kecamatan, 211 desa dan 11 kelurahan[1]. Setiap desa memiliki kondisi ekonomi, ciri dan tipologi lingkungan, akses fasilitas umum yang berbeda dan akan mengalami perubahan seiring dengan kemajuan pembangunan suatu desa. Pemanfaatan potensi yang ada pada setiap daerah perlu diperhatikan, karena melalui pengoptimalan potensi desa dapat mengangkat angka kemiskinan di suatu daerah[2].

Kabupaten Pemalang menduduki tingkat ke-4 teratas dari 35 Kabupaten/kota yang berada di Provinsi Jawa Tengah yang memiliki presentase kemiskinan tertinggi atau dibawah rata - rata sehingga menurut kriteria tipologi daerah termasuk dalam daerah relative tertinggal[1]. Berdasarkan data yang diperoleh dari Badan Pusat Statistik Kabupaten Pemalang tahun 2019, jumlah penduduk miskin di Kabupaten Pemalang sebanyak 200.670 jiwa dengan persentase sebesar 15,41 persen. Kabupaten Pemalang menempati posisi ke empat teratas dalam persentase kemiskinan di Provinsi Jawa Tengah.

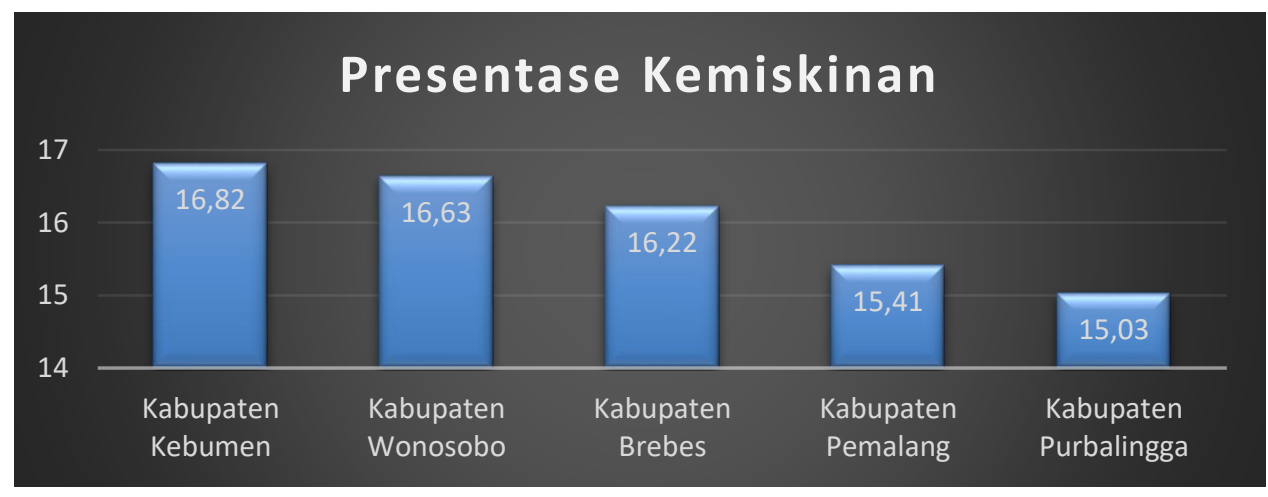

Gambar 1.1 Presentase Kemiskinan di Provinsi Jawa Tengah (2019)

Berdasarkan data dari Badan Pusat Statistik menunjukan kemiskinan sebagian besar dialami oleh masyarakat pedesaan selain itu rendahnya tingkat pelayanan infrastruktur di kawasan pedesaan hal inilah yang menjadi latar belakang kebijakan program pembangunan yang akan dilaksanakan[3]. Permasalahan umum yang dihadapi dalam kehidupan di setiap desa tentu berbeda - beda. Upaya mencapai tujuan pemerintah untuk menciptakan desa mandiri beberapa hal yang sangat perlu untuk dilakukan dan dikembangkan adalah mengutamakan pembangunan sarana dan prasarana yang ada di desa[3]. Pemerataan pembangunan perlu dilakukan untuk memperbaiki masalah kemiskinan[4]. Oleh karena itu, diperlukan sebuah upaya pengelompokan desa agar pengambilan kebijakan menjadi tepat sasaran[5]. Pemerintah pusat mulai memprioritaskan pembangunan dan pemberdayaan masyarakat di suatu daerah sampai tingkat desa agar tidak semakin tertinggal[6].

Dalam pelaksanaannya diperlukan identifikasi kondisi social masyarakat di setiap wilayah agar pengambilan keputusan atau kebijakan mengenai pembangunan bias tepat sasaran[7]. Ketepatan dalam pengidentifikasian target group atau target area menjadi prasyarat dalam keberhasilan program-program pembangunan[8]. Perencanaan pembangunan tidak terlepas dari kondisi masyarakat dan potensi daerah yang dimiliki. Adanya kebijakan pembangunan yang tepat sasaran dapat memberikan dampak positif terhadap jalannya roda perekonomian di suatu wilayah.

Berdasarkan latar belakang tersebut, akan dilakukan penelitian mengenai analisis cluster untuk pengelompokan desa di daerah Kabupaten Pemalang berdasarkan data Potensi Desa Kabupaten Pemalang. Analisis cluster adalah salah satu metode yang bertujuan untuk mengelompokkan data berdasarkan kemiripan karakteristik yang dimiliki dalam satu cluster yang sama. Potensi desa diamati berdasarkan ketersediaan infrastruktur serta keadaan sosial yang dimiliki oleh desa/kelurahan/nigari.

Salah satu algoritma clustering yang banyak digunakan adalah algoritma K-Means karena cukup sederhana, mudah diimplementasikan, dan memiliki kemampuan untuk mengelompokkan data yang besar dengan sangat cepat[9]. Namun algoritma K-Means memiliki kelemahan pada penentuan pusat cluster awal yang diberikan[10]. Pada K-Means, pusat cluster awal ditentukan secara acak atau random. Inisialisasi pusat cluster secara acak dapat memberikan hasil pembentukan cluster yang berubah-ubah (tidak konsisten) sehingga terkadang membutuhkan waktu yang cukup lama dalam melakukan iterasi untuk menemukan output cluster akhir. Inisialisasi pusat cluster yang tidak konsisten juga dapat menyebabkan masalah local optimum pada proses K-Means konvensional[11]. Untuk itu, metode K-Means perlu dikombinasikan 
dengan metode hirarki dalam penentuan pusat cluster awal[10]. Metode kombinasi ini disebut sebagai Hierarchical K-Means yang merupakan penggabungan antara metode hierarchical dan partitioning, di mana proses hierarchical digunakan untuk mencari inisialisasi pusat cluster awal dan proses partitioning untuk mendapatkan cluster yang optimal. Metode hirarki yang akan diimplementasikan pada penelitian ini adalah metode single linkage.

Penelitian analisis cluster telah dilakukan oleh dilakukan oleh Alfina dkk., 2012 yang melakukan perbandingan antara metode Hierarchical Clustering, K-Means, dan gabungan keduanya dalam pengelompokan data problem kerja praktek jurusan Teknik Industri ITS. Berdasarkan penelitian yang dilakukan, diperoleh hasil bahwa kombinasi algoritma hierarchical clustering dan $k$-means menghasilkan pengelompokan data yang lebih baik dibandingkan k-means biasa. Dari kombinasi tersebut, diketahui kombinasi single linkage dan $k$-means yang menghasilkan cluster terbaik dibanding metode hirarki lainnya dilihat dari penjumlahan nilai silhouette coefficient terbesar yang dihasilkan[10]. Berdasarkan penelitian yang telah dilakukan sebelumnya, maka penggunaan algoritma $K$-Means memerlukan kombinasi untuk penentuan pusat cluster awal serta menentukan jumlah $\mathrm{k}$ yang digunakan untuk mencapai hasil cluster yang lebih baik. Pada penelitian ini melakukan clustering data menggunakan kombinasi single linkage dan $k$ means, penentuan jumlah $\mathrm{k}$ yang digunakan diperoleh dari metode elbow kemudian hasil cluster divalidasi menggunakan silhouette coefficient dan Davies Boulldin Index.

\section{Metode Penelitian} peneliti :

Berikut adalah flowchart penelitian yang berisi tahapan - tahapan penelitian yang dilakukan oleh

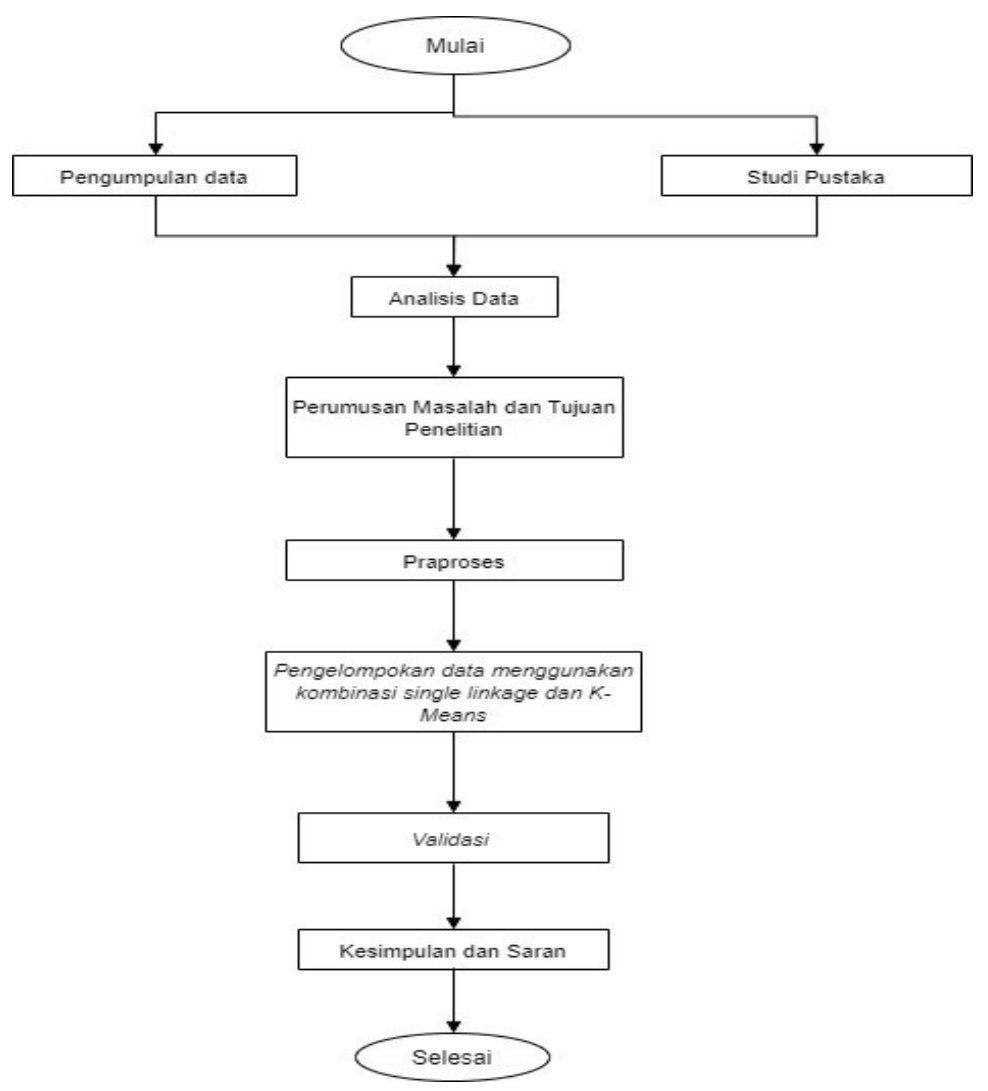

Gambar 1 Tahapan - Tahapan Penelitan

1. Pengumpulan data dan studi Pustaka, teknik pengumpulan data yang digunakan data dilakukan secara sekunder, selain itu dilakukan wawancara dengan pihak Badan Pusat Statistik Kabupaten Pemalang untuk menghimpun informasi mengenai potensi desa dengan parameter yang terlibat didalamnya dan studi pustaka dilakukan untuk menggali informasi lebih lanjut mengenai hal yang dibutuhkan saat penelitian. 
2. Perumusan masalah dan tujuan penelitian, perumusan masalah serta tujuan penelitian yang ingin dicapai dalam penelitian ini yang didasarkan pada hasil analisa data pada taham sebelumnya.

3. Praproses bertujuan untuk mempermudah dalam pemahaman terhadap isi record. Praproses yang dimaksud yaitu menyamakan satuan data atau menstandarisasikan data, untuk mengetahui adanya multikolinearitas antar variable dengan uji multikolinearitas menghitung nilai VIF (Variance Inflation Factors), serta mengukur kecukupan sampling secara menyeluruh dengan uji Kaiser Mayer Olkin (KMO) .

4. Penerapan metode, pada penerapan metode ini akan diuraikan langkah-langkah sistematis dan terarah menggunakan urutan metode single linkage yang di gunakan di tahap awal sedangkan $k$ means di tahap akhir.

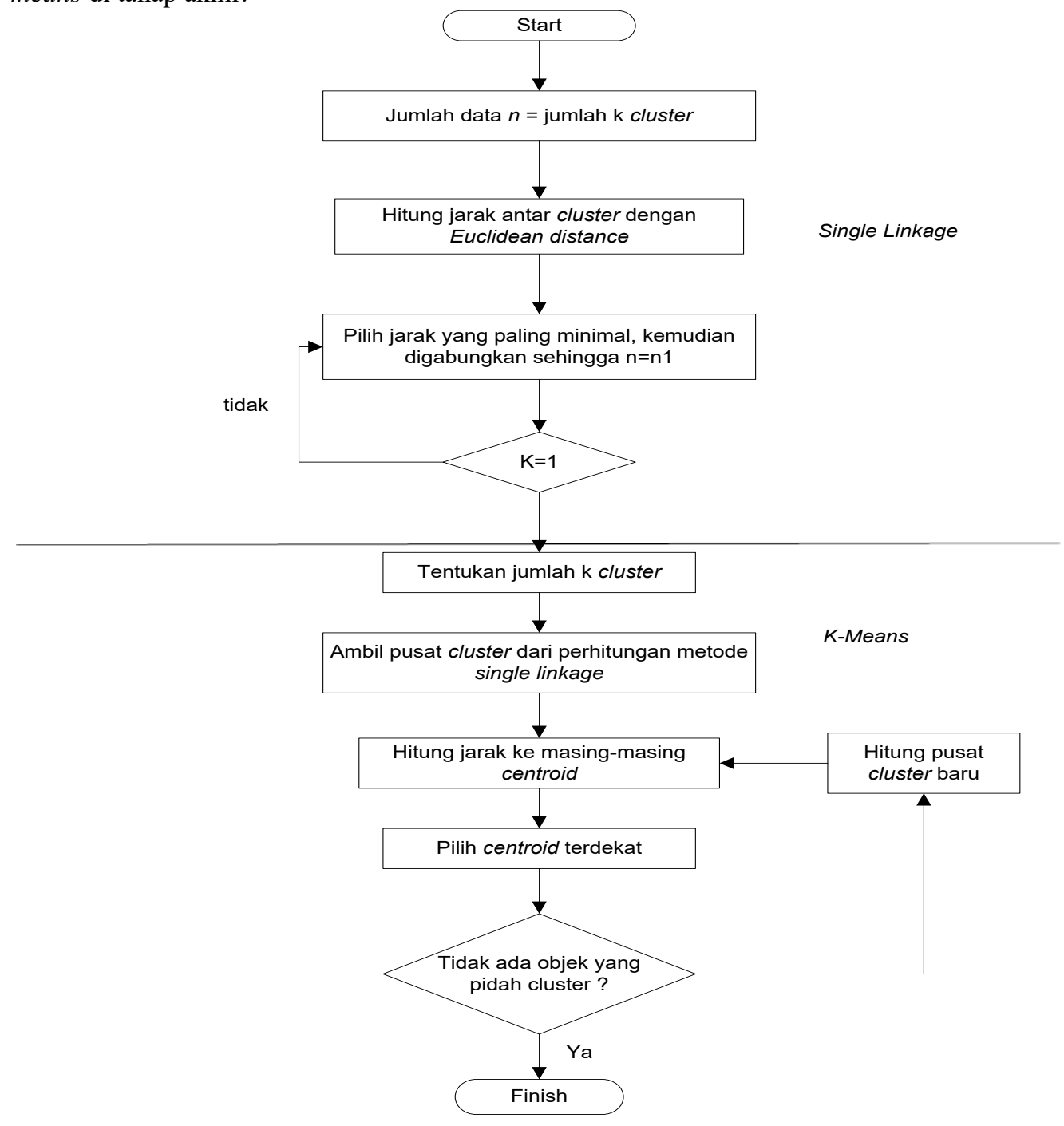

Gambar 2 Kombinasi Single Linkage dan K-Means

5. Validasi, pada proses validasi dilakukan pengukuran kualitas cluster yang terbentuk menggunakan silhouette coefficient dan Davies Boulldin Index.

6. Kesimpulan dan saran, penarikan kesimpulan dan saran berdasarkan hasil penelitian yang telah dilakukan 
Asumsi analisis cluster diperlukan untuk memeriksa variable - variable yang ada dan memastikan apakah variable layak digunakan dalam penelitian atau tidak. Dalam hal ini untuk mendeteksi multikolinearitas atau korelasi antar variable predictor menggunakan VIF (Variance Inflation Factors) dan untuk mengecek sampel yang mewakili atau sampel representative menggunakan uji Kaiser Mayer Olkin (KMO).

\section{a. Multikolinearitas}

Multikolinieritas merupakan suatu keadaan dimana terdapat korelasi antar variabel prediktor[12]. Salah satu cara yang dapat digunakan untuk mendeteksi adanya multikolinearitas yaitu dengan menghitung nilai VIF (Variance Inflation Factors) pada variabel yang diteliti [12] VIF dapat dihitung dengan rumus :

$$
V I F=\frac{1}{1-R^{2}}
$$

dengan $\mathrm{R}^{2}$ yang merupakan koefisien determinasi variabel dependen dengan variabel independen[13]. Jika nilai VIF lebih besar dari 10 menunjukkan adanya multikolinieritas antara variabel-variabel prediktor.

b. Sampel Yang Mewakili

Sampel yang mewakili atau sampel representatfif merupakan sampel yang merepresentasikan atau mewakili populasi yang ada. Untuk mendeteksi hal tersebut dapat dilakukan dengan uji Kaiser Mayer Olkin (KMO). Sampel dapat dikatakan mewakili populasi atau sampel representative jika nilai KMO berada direntang 0,5 sampai dengan 1 .

\section{Penentuan Jumlah Cluster Optimum}

Pada metode partitioning, jumlah atau banyaknya cluster $(\mathrm{k})$ ditentukan terlebih dahulu. Penentuan jumlah cluster menggunakan metode Elbow[14]. Metode Elbow adalah metode yang digunakan untuk memperoleh informasi mengenai jumlah cluster terbaik yang sebaiknya digunakan pada penelitian dengan cara melihat presentase hasil berbandingan antara jumlah cluster yang akan membentuk siku pada suatu titik[15]. Penentuan jumlah cluster pada metode ini dapat dihasilkan dari perbandingan hasil Sum of Square Error (SSE) pada masing - masing jumlah cluster dengan rumus SSE sebagai berikut (Irwanto dkk., 2012, seperti dikutip Merliana, 2015:17):

$$
S S E=\sum_{k=1}^{k} \sum_{x \mathrm{i} \in C k}\left\|x_{i}-C_{k}\right\|^{2}
$$

$$
\begin{aligned}
& \text { dengan, } \\
& \mathrm{x}_{\mathrm{i}}=\text { data pada objek ke- } \mathrm{i} \\
& \mathrm{c}_{\mathrm{k}}=\text { centroid cluster } \mathrm{C}_{\mathrm{k}}
\end{aligned}
$$

Hasil Sum of Square Error (SSE) akan di representasikan dengan grafik sebagai sumber informasi [15]

\section{Pemilihan Ukuran Jarak}

Ukuran jarak digunakan untuk mengukur kemiripan antara dua objek. Salah satu ukuran jarak yang umum digunakan dalam clustering adalah jarak Euclidean [16]. Jarak Euclidea nmerupakan jarak dari suatu garis lurus yang menghubungkan antar objek[16]. Jarak Euclidean merupakan akar dari jumlah kuadrat perbedaan di dalam nilai untuk setiap variabel[12] (Supranto, 2004) :

$$
d(i, j)=\sqrt{\left(x_{i 1}-x_{j 1}\right)^{2}+\left(x_{i 2}-x_{j 2}\right)^{2}+\cdots+\left(x_{i k}-x_{j k}\right)^{2}}
$$

dengan :

$$
\begin{array}{cl}
d(i, j) & =\text { Jarak dari data } \mathrm{i} \text { ke data } \mathrm{j} \\
x_{i k} & =\text { Data } \mathrm{i} \text { pada atribut data } \mathrm{k} \\
x_{j k} & =\text { Data ke-j pada atribut data } \mathrm{k}
\end{array}
$$

\section{Metode Single Linkage}

Single linkage adalah proses clustering yang didasarkan pada jarak terdekat antar objeknya (minimum distance). Metode ini akan menggabungkan dua buah objek yang memiliki jarak terdekat menjadi satu kelompok [12]. Anggota suatu cluster akan bertambah jika ada suatu variable yang memiliki jarak terdekat pada suatu cluster sehingga akan terjadi proses pengelompokkan secara hirarki [16]. Hasil dari metode single linkage dapat disajikan dalam bentuk diagram pohon atau dendogram.

Untuk menentukan jarak antar cluster menggunakan metode single linkage dapat dilakukan dengan perhitungan berikut : 


$$
d_{(U V) W}=\min \left\{d_{U W}, d_{V W}\right\}
$$

di mana $d_{U W}$ dan $d_{V W}$ merupakan jarak cluster $\mathrm{U}$ dengan cluster $\mathrm{W}$ dan jarak cluster $\mathrm{V}$ dengan cluster $\mathrm{W}[12]$.

\section{Metode K-Means}

Algoritma $K$-Means adalah salah satu algoritma clustering yang digunakan untuk mengelompokkan data berdasarkan titik pusat cluster (centroid) yang dekat dengan data, yang bertujuan untuk memaksimalkan kemiripan data dalam satu cluster serta meminimalkan kemiripan data antar cluster[17]. Menurut [18], untuk melakukan clustering dengan metode $K$-Means adalah sebagai berikut :

1.Menentukan jumlah cluster data atau k yang akan digunakan

2. Menentukan titik centroid atau pusat cluster.

3. Alokasikan semua data atau objek ke dalam cluster yang jaraknya paling dekat.

4. Hitung ulang pusat cluster dengan keanggotaan yang sekarang.

Tugaskan lagi setiap objek memakai cluster yang baru. Apabila pusat cluster yang diperoleh tidak berubah maka akan proses selesai. Jika tidak maka akan kembali ke langkah 3.

\section{Gabungan Metode Single Linkage Dengan K-Means 28}

Metode single linkage merupakan salah satu dari metode Hierarchical Clustering, proses hierarchical digunakan untuk menentukan titik pusat cluster awal yang selanjutnya titik pusat cluster tersebut digunakan untuk proses pengelompokan data menggunakan metode k-means[10] [19] Gabungan metode ini dikembangkan dengan tujuan meningkatkan kualitas pengelompokkan data, waktu yang dibutuhkan untuk proses pengelompokkan lebih cepat terutama untuk big data.[20]

\section{Validasi}

Setelah pengelompokan data maka dilakukan evaluasi hasil pengelompokan menggunakan validasi cluster. Validasi cluster dilakukan untuk mengukur kualitas cluster yang dihasilkan dari pengelompokan yang telah dilakukan[21]. Penelitian ini menggunakan validasi adalah Silhouette Coefficient dan Davies Boulldin Index.

Silhouette Coefficient adalah salah satu metode validasi cluster yang digunakan untuk melihat tingkat kualitas dan kekuatan cluster suatu objek di dalam suatu cluster[22]. Nilai Silhouette Coefficient dirumuskan sebagai berikut :

dengan,

$$
s(i)=\frac{(b(i)-a(i))}{\operatorname{Max}\{a(i), b(i)}
$$

$a(i)=$ rata - rata jarak objek ke- $i$ terhadap semua objek di klaster A

$b(i)=$ nilai minimal rata - rata jarak objek ke- $i$ terhadap semua objek di klaster lain.

Tabel berikut menyajikan kriteria pengukuran nilai silhouette coefficient [21]

\begin{tabular}{c|c}
\multicolumn{2}{c}{ Tabel 1 Kriteria Pengukuran Nilai Silhouette coefficient } \\
\hline Silhouette Coefficient & Kriteria \\
\hline $0,71-1,00$ & $\begin{array}{c}\text { Cluster yang kuat } \\
0,51-0,70 \\
0,26-0,50 \\
<=0,25\end{array}$ \\
$\begin{array}{c}\text { Cluster yang layak atau sesuai } \\
\text { Cluster yang lemah } \\
\text { Tidak dapat dikatakan sebagai Cluster }\end{array}$ \\
\hline
\end{tabular}

sumber: Kaufmaan dan Rousseeuw,2005:85

Davies Bouldin Index (DBI) pertama kali diusulkan di tahun 1979 oleh David L. Davies dan Donald W.Bouldin . DBI ini mempunyai skema evaluasi cluster internal baik atau tidaknya cluster yang dihasilkan dapat dilihat dari kuantitas dan kedekatan antar data dari hasil cluster. [23]

DBI dilakukan dengan cara yaitu memaksimalkan jarak didalam sebuah cluster serta meminimalkan jarak diluar cluster[24]. Semakin kecil nilai DBI menunjukkan cluster yang dihasilkan optimal[25]. Nilai DBI dirumuskan pada persamaan : 


$$
D B I=\frac{1}{K} \sum_{i=1}^{k}\left\{R_{\mathrm{i}}\right\}
$$

dengan:

$\mathrm{k}$ : jumlah cluster

$\mathrm{R}_{\mathrm{i}}$ : Ukuran kemiripan

\section{Hasil dan Pembahasan}

Hasil Uji Multikolinearitas

Untuk pengujian multikoliniaritas antar variabel dapat ditentukan dengan cara melihat nilai tolerance dan VIF yang dihasilkan. Berdasarkan tabel dibawah nilai tolerance lebih besar dari 0,10 serta nilai VIF $<10$ oleh karena itu dapat disimpulkan bahwa tidak terjadi gejala multikolinearitas antar variabel.

Tabel 2 . Nilai VIF

Coefficients $^{\mathrm{a}}$

\begin{tabular}{|c|c|c|c|c|c|c|c|}
\hline \multirow[b]{2}{*}{ Model } & \multicolumn{2}{|c|}{$\begin{array}{c}\text { Unstandardized } \\
\text { Coefficients }\end{array}$} & \multirow{2}{*}{$\begin{array}{c}\text { Standardized } \\
\text { Coefficients } \\
\text { Beta } \\
\end{array}$} & \multirow[b]{2}{*}{$\mathbf{t}$} & \multirow[b]{2}{*}{ Sig. } & \multicolumn{2}{|c|}{$\begin{array}{c}\text { Collinearity } \\
\text { Statistics } \\
\end{array}$} \\
\hline & B & \begin{tabular}{c|} 
Std. \\
Error \\
\end{tabular} & & & & Tolerance & VIF \\
\hline (Constant) & 3.563 & .000 & & 755583097.871 & .000 & & \\
\hline Zscore(X1) & 2.532 & .000 & 1.000 & 215268258.029 & .000 & .161 & 6.192 \\
\hline Zscore(X2) & $-9.143 \mathrm{E}-15$ & .000 & .000 & .000 & 1.000 & .390 & 2.566 \\
\hline Zscore(X3) & $-2.784 \mathrm{E}-15$ & .000 & .000 & .000 & 1.000 & .583 & 1.715 \\
\hline Zscore(X4) & $6.598 \mathrm{E}-15$ & .000 & .000 & .000 & 1.000 & .517 & 1.936 \\
\hline Zscore(X5) & $8.066 \mathrm{E}-15$ & .000 & .000 & .000 & 1.000 & .479 & 2.088 \\
\hline Zscore(X6) & $4.089 \mathrm{E}-15$ & .000 & .000 & .000 & 1.000 & .622 & 1.609 \\
\hline Zscore $(X 7)$ & $-4.732 \mathrm{E}-15$ & .000 & .000 & .000 & 1.000 & .549 & 1.821 \\
\hline Zscore(X8) & $-3.412 \mathrm{E}-16$ & .000 & .000 & .000 & 1.000 & .142 & 7.046 \\
\hline Zscore(X9) & $3.870 \mathrm{E}-15$ & .000 & .000 & .000 & 1.000 & .108 & 9.251 \\
\hline Zscore(X10) & $-1.585 \mathrm{E}-15$ & .000 & .000 & .000 & 1.000 & .238 & 4.205 \\
\hline Zscore (X11) & $2.055 \mathrm{E}-14$ & .000 & .000 & .000 & 1.000 & .162 & 6.169 \\
\hline Zscore(X12) & $2.654 \mathrm{E}-14$ & .000 & .000 & .000 & 1.000 & .226 & 4.422 \\
\hline Zscore(X13) & $-2.459 \mathrm{E}-15$ & .000 & .000 & .000 & 1.000 & .745 & 1.343 \\
\hline Zscore(X14) & $2.499 \mathrm{E}-15$ & .000 & .000 & .000 & 1.000 & .924 & 1.082 \\
\hline Zscore(X15) & $1.850 \mathrm{E}-15$ & .000 & .000 & .000 & 1.000 & .842 & 1.187 \\
\hline
\end{tabular}

\section{Hasil Uji Sampel Yang Mewakili Dengan KMO}

Berdasarkan Bartlet Test of Sphericity dengan Chi-Square 1940.466 (df 105) dengan nilai sig $=0,000$ $<0,05$ menunjukkan bahwa matriks korelasi bukan merupakan jenis matriks identitas oleh karena itu variable yang digunakan dapat dilakukan analisis komponen utama. Selain itu nilai KMO yang di hasilkan adalah 0,767 Berdasarkan nilai KMO dan Bartlett's test tersebut, dapat disimpulkan bahwa semua variabel layak untuk dianalisis dengan variabel yang dapat diolah lebih lanjut sebanyak 15 variabel.

Tabel 3 KMO and Bartlett's Test

\begin{tabular}{|c|c|c|}
\hline \multicolumn{3}{|l|}{ KMO and Bartlett's Test } \\
\hline \multicolumn{2}{|c|}{ Kaiser-Meyer-Olkin Measure of Sampling Adequacy. } & .767 \\
\hline Bartlett's Test of Sphericity & Approx. Chi-Square & 1940.466 \\
\hline & df & 105 \\
\hline & Sig. & .000 \\
\hline
\end{tabular}

Penentuan Jumlah Cluster Optimum Dengan Metode Elbow 
Gambar dibawah merupakan plot metode elbow antara nilai SSE dengan banyaknya klaster (k) yang terbentuk. Nilai k atau banyaknya klaster yang akan dibentuk dapat dilihat ketika terjadi penurunan drastis dan terbentuk siku (elbow) untuk nilai SSE pada suatu nilai k. Pada plot di tersebut, nilai SSE mengalami penurunan drastis, dari $\mathrm{k}=1$ sampai $\mathrm{k}=4$ dan turun secara perlahan pada nilai $\mathrm{k}$ berikutnya hingga relatif stabil. Garis membentuk elbow pada $k=4$, dan setelahnya nilai SSE pada plot relatif stabil. Sehingga dapat diambil kesimpulan bahwa banyaknya klaster yang dibentuk adalah 4 klaster

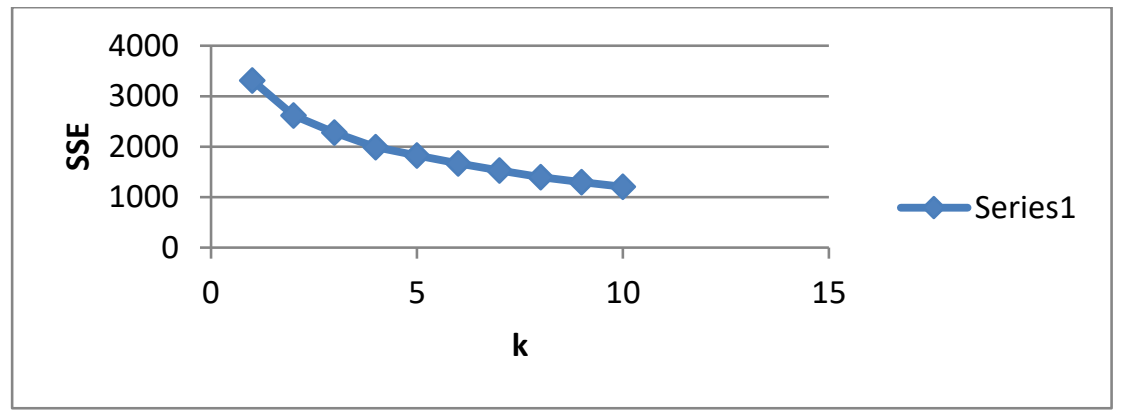

Gambar 3 Grafik Metode Elbow

\section{Hasil Proses Single Linkage}

Proses clustering menggunakan metode single lingkage dimana setiap data akan dianggap sebagai cluster, jika terdapat data sejumlah $\mathrm{n}$, kemudian $\mathrm{k}$ dianggap sebagai jumlah cluster, maka besarnya $\mathrm{n}=\mathrm{k}$. Selanjutnya akan dihitung jarak antar clusternya menggunakan Euclidean distance dari hasil perhitungan jarak tersebut dipilih jarak yang paling minimal untuk digabungkan menjadi sebuah cluster sehingga besarnya $\mathrm{n}=\mathrm{n}-1$ dan berhenti jika $\mathrm{k}=1$. Berdasarkan proses single linkage yang telah dilakukan, akan diambil titik pusat untuk $\mathrm{k}=4$ dimana titik pusat ini akan digunakan untuk proses clustering selanjutnya menggunakan metode $k$-means.

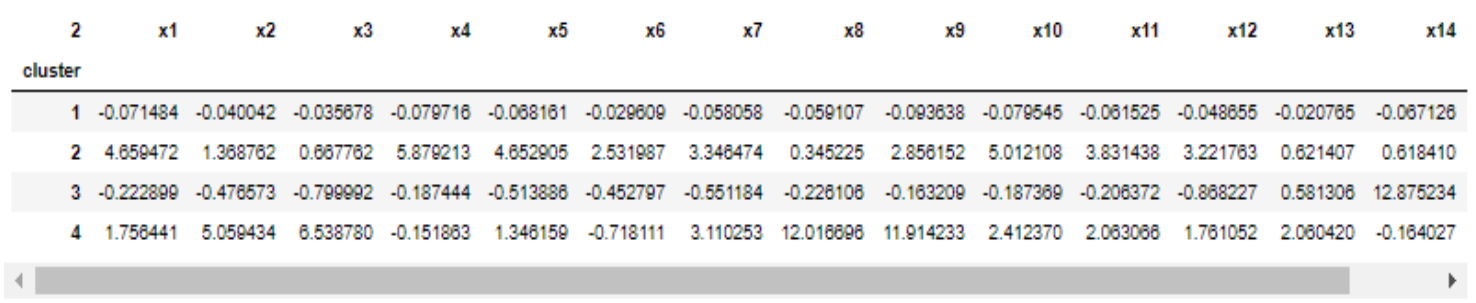

Gambar 4 Hasil Single Linkage

\section{Hasil Gabungan Metode Single Linkage dan K-Means}

Pada tahap ini titik pusat yang akan digunakan pada proses clustering dengan $k$-means berasal dari proses single linkage. Hasil dari proses clustering menggunakan metode gabungan antara single linkage dengan $k$-means ini yaitu sebagai berikut :

Klaster 0

Plakaran, Mandiraja, Walangsanga, Sima, Moga, Wangkelang, Kebanggan, Pepedan, Gendowang, Pakembaran, Warungpring, Karangdawa, Datar, Cibuyur, Mereng, Clekatakan, Batursari, Penakir, Gunungsari, Jurangmangu, Gambuhan, Karangsari, Nyalembeng, Pulosari, Pagenteran, Siremeng, Cikendung, Gombong, Belik, Gunungtiga, Kuta, Badak, Gunungjaya, Simpur, Mendelem, Beluk, Bulakan, Sikasur, Kalisaleh, Tundagan, Tlagasana, Bongas, Cikadu, Cawet, Medayu, Pagelaran, Bodas, Jojogan, Majalangu, Tambi, Watukumpul, Gapura, Majakerta, Wisnu, Longkeyang, Jatingarang, Gunungbatu, Pasir, Kwasen, Jatiroyom, Parunggalih, Payung, Cangak, Kebandungan, Kesesirejo, Babakan, Karangbrai, Jraganan, Kebandaran, Bodeh, Muncang, Kelangdepok, Pendowo, Sumurkidang, Wanarata, Pedagung, Suru, Banjarsari, Pegiringan, Karanganyar, Purana, Pabuaran, Sarwodadi, Bantarbolang, Sambeng, Glandang, Kuta, Kebon Gede, Paguyangan, Lenggerong, Kecepit, Gembyang, Mejagong, Penusupan, Banjaranyar, Karangmoncol, Semingkir, Semaya, Tanahbaya, Lodaya, Rembul, Kreyo, Kalimas, Mangli, Kalitorong, Kejene, Gongseng, Banjarmulya, Surajaya, Pagongsoran, Sungapan, Paduraksa, Kramat, 
Wanamulya, Mengori, Sewaka, Saradan, Bojongbata, Bojongnangka, Tambakrejo, Lawangrejo, Widuri, Danasari, Penggarit, Pener, Gondang, Jrakah, Sokawangi, Kejambon, Jebed Selatan, Jebed Utara, Cibelok, Kaligelang, Banjardawa, Banjaran, Sitemu, Pedurungan, Taman, Wanarejan Selatan, Wanarejan Utara, Beji, Kabunan, Asemdoyong, Kedungbanjar, Kendalsari, Widodaren, Karangasem, Sirangkang, Iser, Serang, Petarukan, Kalirandu, Pesucen, Panjunan, Temuireng, Pegundan, Bulu, Tegalmlati, Loning, Nyamplung Sari, Klareyan, Kendaldoyong, Kendalrejo, Sokawati, Tegalsari Barat, Tegalsari Timur, Kemuning, Karangtalok, Wonogiri,Blimbing, Ampelgading, Cibiyuk, Karangtengah, Banglarangan, Losari, Ujunggede, Jatirejo, Kebagusan, Sidokare, Tumbal, Pecangakan, Sikayu, Purwosari, Purwoharjo, Kauman, Sidorejo, Lowa, Ambokulon, Gedeg, Gintung, Gandu, Sarwodadi, Susukan, Klegen, Wonokromo, Kebojongan, Kandang, Sukorejo, Botekan, Rowosari, Ambowetan, Pagergunung, Wiyorowetan, Samong, Tasikrejo, Bumirejo, Kaliprau, Kertosari, Pamutih, Padek, Blendung, Ketapang, Limbangan, Mojo, Pesantren

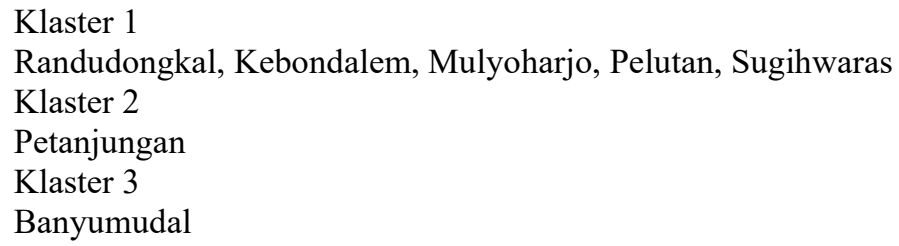

Perbandingan kualitas cluster menggunakan metode K-Means dan kombinasi Single Linkage dengan K-means

Berikut adalah hasil dari penerapan algoritma $K$-Means dan Kombinasi algoritma $K$-Means dengan Single Linkage yang telah dilakukan menghasilkan informasi validasi cluster dari data potensi desa menggunakan variasi nilai $\mathrm{k}$.

Tabel 4 Hasil Perbandingan Evaluasi Model

\begin{tabular}{c|c|c|c|c}
\hline \multirow{2}{*}{$\begin{array}{c}\text { Jumlah } \\
\text { Cluster }\end{array}$} & \multicolumn{2}{|c|}{ K-means } & \multicolumn{2}{c}{ Kombinasi Single Linkage \& K-Means } \\
\cline { 2 - 5 } & $\begin{array}{c}\text { silhouette } \\
\text { coefficient }\end{array}$ & $\begin{array}{c}\text { Davies Boulldin } \\
\text { Index. }\end{array}$ & $\begin{array}{c}\text { silhouette } \\
\text { coefficient }\end{array}$ & $\begin{array}{c}\text { Davies Boulldin } \\
\text { Index. }\end{array}$ \\
\hline 3 & 0.346 & 1.206 & 0.670 & 0.727 \\
4 & 0.370 & 1.313 & 0.685 & 0.577 \\
5 & 0.367 & 1.012 & 0.299 & 0.986 \\
\hline
\end{tabular}

Berdasarkan tabel diatas kualitas cluster yang dihasilkan oleh gabungan metode single linkage dan $k$-means lebih baik dibandingkan dengan cluster yang hanya dibentuk oleh metode $k$-means. Berdasarkan hasil evaluasi tersebut dapat disimpulkan bahwa kombinasi algoritma single linkage dan $k$-means dengan k = 4 menghasilkan nilai evaluasi yang paling baik dibandingkan dengan menggunakan algoritma $K$-Means tanpa kombinasi. Kombinasi antara metode single linkage yang digunakan untuk menentukan pusat cluster dan $k$-means terbukti dapat memperbaiki kualitas klaster yang dihasilkan.

\section{Pengaruh Single Linkage dalam proses clustering}

Pada penelitian ini single linkage digunakan untuk mencari centroid yang akan digunakan pada proses clustering $k$-means. Dari hasil penelitian yang sudah dilakukan diperoleh hasil bahwa kualitas kluster yang dihasilkan dari penggabungan metode single linkage dan k-means rata - rata menghasilkan cluster yang layak sedangkan jika menggunakan metode k-means saja atau tanpa kombinasi semua cluster yang dihasilkan merupakan cluster yang lemah.

\section{Kebijakan pembangunan yang dapat dilakukan}

Berdasarkan penelitian yang telah dilakukan untuk desa yang berada pada cluster nol Contoh pembangunan sarana prasarana di bidang ekonomi yang dapat dilakukan yaitu pembangunan minimarket atau pasar sebagai tempat bertransaksi untuk mendukung berkembangnya roda ekonomi ditingkat masyarakat, selain itu pembangunan fasilitas kesehatan dan distribusi tenaga kesehata didesa ini perlu dilakukan pemerataan agar semua masyarakat bias mendapatkan kemudahan dalam hal pengobatan. 
Untuk desa yang berada pada cluster dua pembangunan infrastruktur yang dapat dilakukan yaitu membangun infrastruktur kesehatan contohnya puskesmas, jumlah tenaga kesehatan pada cluster ini tergolong minim sehingga diperlukan pemerataan tenaga kesehatan. Pembannan minimarket maupun pasar tradisionalpun perlu dilakukan untuk mendukung berkembangnya roda ekonomi masyarakat. Untuk cluster satu hanya perlu dilakukan pemeliharan fasilitas desa karena desa yang berada pada cluster tersebut sarana prasarananya sangat baik sedangkan untuk desa yang berada pada cluster tiga pembangunan yang perlu dilakukan yaitu yaitu sector pariwisatanya, pembangunan sarana prasarana untuk mengembangkan potensi alam yang ada perlu dilakukan contohnya dengan membangun penginapan, membangun took atau warung disekitar tempat wisata, maupun akses menuju tempat wisata tersebut

\section{Kesimpulan}

Berdasarkan penelitan yang dilakukan diperoleh bahwa cluster terbaik berdasarkan metode elbow yaitu $\mathrm{k}=4$. Hasil klaster dari kombnasi metode Single Linkage dan K-Means dapat diketahui bahwa cluster 0 merupakan kelompok desa yang kurang maju, ditinjau dari sarana prasarana desa, keadaan social penduduknya yang dicerminkan oleh rendahnya fasilitas pendidikan, kesehatan dibandingkan klaster yang lainnya. cluster 1 terdiri dari desa yang paling maju ditinjau dari faktor sarana dan prasarana desa serta faktor social ekonoki penduduknya. Umumnya desa - desa yang ada dalam kelompok ini merupakan kategori yang dekat dengan pusat kota. Cluster 2 merupakan kelompok desa yang memiliki ciri daerah yang paling tertinggal dibandingkan dengan kelompok lainnya. Cluster 3 adalah adalah kelompok desa yang terdiri dari desa yang cukup maju ditinjau dari faktor sarana dan prasarana desa, termasuk faktor social ekonomi penduduknya, namun secara keseluruhan nilai faktornya masih dibawah klaster 1 .

Kualitas cluster yang dihasilkan oleh gabungan metode single linkage dan $k$-means lebih baik dibandingkan dengan cluster yang hanya dibentuk oleh metode $k$-means. Berdasarkan hasil evaluasi tersebut dapat disimpulkan bahwa kombinasi algoritma single linkage dan $k$-means dengan $\mathrm{k}=4$ menghasilkan nilai evaluasi yang paling baik.

\section{Daftar Pustaka}

[1] Badan Pusat Statistik, "Statistik Potensi Desa Kabupaten Pemalang 2019,” pp. 1-131, 2019.

[2] A. Supandi, A. Saefuddin, and I. D. Sulvianti, "Two step Cluster Application to Classify Villages in Kabupaten Madiun Based on Village Potential Data," Xplore J. Stat., vol. 10, no. 1, pp. 12-26, 2020, doi: 10.29244/xplore.v10i1.272.

[3] T. Alya and S. Sjaf, "ANALISIS RESPON MASYARAKAT TERHADAP PENGELOLAAN DANA DESA UNTUK PEMBANGUNAN PEDESAAN ( Desa Pesantren , Kecamatan Ulujami, Kabupaten Pemalang ) Analysis of Community Response towards The Management of Village Fund for Rural," Sains Komun. dan Pengemb. Masy., vol. 2, no. 3, pp. 317-332, 2018.

[4] N. Irabawati, S. Wahyuningsih, and R. R. Syoer, "Perbandiangan Metode C-Means dan Fuzzy CMeans Dalam pengelompokkan Wilayah Desa/Kelurahan di Kabupaten Kutai Kartanegara,” vol. 7, pp. 1-13, 2014.

[5] W. Alwi and M. Hasrul, "Analisis Klaster Untuk Pengelompokkan Kabupaten/Kota Di Provinsi Sulawesi Selatan Berdasarkan Indikator Kesejahteraan Rakyat,” J. MSA ( Mat. dan Stat. serta Apl. ), vol. 6, no. 1, p. 35, 2018, doi: 10.24252/msa.v6i1.4782.

[6] Z. S. Badu, "Penerapan Algoritma K-Nearest Neighbor Untuk Klasifikasi Dana Desa," J. Inform., no. November, 2016,

[7] Y. B. Alam and A. N. Ambarwati, "Analisis Cluster Pada Desa / Kelurahan Di Kabupaten Wonosobo Berdasarkan Data Potensi Desa Tahun 2015,” no. February, pp. 351-358, 2017.

[8] Soemartini and E. Supartini, “Analisis K-Means Cluster Untuk Pengelompokan Kabupaten / Kota Di Jawabarat Berdasarkan Indikator Masyarakat,” Prosiding, no. Knpmp Ii, pp. 144-154, 2017.

[9] A. S. Rizal and R. F. Hakim, "Metode K-Means Cluster Dan Fuzzy C-Means Cluster (Studi Kasus: Indeks Pembangunan Manusia Di Kawasan Indonesia Timur Tahun 2012)," Pros. Semin. Nas. Mat. dan Pendidik. Mat. UMS 2015, pp. 643-657, 2015, [Online]. Available: https://publikasiilmiah.ums.ac.id/xmlui/handle/11617/5803.

[10] T. Alfina and B. Santosa, "Analisa Perbandingan Metode Hierarchical Clustering, K-Means dan Gabugan Keduanya dalam Membentuk Cluster Data (Studi Kasus : Problem Kerja Praktek Jurusan Teknik Industri ITS)," Anal. PerbandinganMetode Hierarchical Clust. K-means dan Gabungan Keduanya dalam Clust. Data, vol. 1, no. 1, pp. 1-5, 2012, doi: 10.12962/j23373539.v1i1.1794.

[11] S. Q. Ye Hanmin, Lv Hao, “An Improved Semi-Supervised K-Means Clustering Algorithm,” pp. $5-8$. 
[12] A. N. Fathia and R. Rahmawati, "Analisis klaster kecamatan di kabupaten semarang berdasarkan potensi desa menggunakan metode ward dan single linkage," vol. 5, pp. 801-810, 2016.

[13] D. N. Gujarati and D. C. Porter, "Dasar-dasar ekonometrika," Jakarta: Erlangga, 2006.

[14] S. H. Ghwanmeh, "Applying Clustering of Hierarchical K-means-like Algorithm on Arabic Language,” vol. 1, no. 8, pp. 2390-2394, 2007.

[15] N. Putu, E. Merliana, and A. J. Santoso, “Analisa Penentuan Jumlah Cluster Terbaik pada Metode K-Means," pp. 978-979.

[16] K. U. Mengelompokkan and K. Di, "LINKAGE , COMPLETE LINKAGE , AVERAGE LINKAGE, DAN JAWA TENGAH BERDASARKAN PRODUKSI PALAWIJA,” 2017.

[17] R. A. Asroni, "Penerapan Metode K-Means Untuk Clustering Mahasiswa Berdasarkan Nilai Akademik Dengan Weka Interface Studi Kasus Pada Jurusan Teknik Informatika UMM Magelang," Ilm. Semesta Tek., vol. 18, no. 1, pp. 76-82, 2015, doi: 10.1038/hdy.2009.180.

[18] B. Santosa, "Data mining teknik pemanfaatan data untuk keperluan bisnis," Yogyakarta Graha Ilmu, vol. 978, no. 979, p. 756, 2007.

[19] L. Rahmawati, S. Widya Sihwi, and E. Suryani, "Analisa Clustering Menggunakan Metode KMeans Dan Hierarchical Clustering (Studi Kasus: Dokumen Skripsi Jurusan Kimia, Fmipa, Universitas Sebelas Maret)," J. Teknol. Inf. ITSmart, vol. 3, no. 2, p. 66, 2016, doi: 10.20961/its.v3i2.654.

[20] T. Xu, H. Chiang, G. Liu, and C. Tan, "Hierarchical K-means Method for Clustering Large-Scale Advanced Metering Infrastructure Data," vol. 8977, no. c, 2015, doi: 10.1109/TPWRD.2015.2479941.

[21] D. F. Azuri, Zulhanif, and R. S. Pontoh, "Pengelompokkan Kabupaten/Kota Di Pulau Jawa Berdasarkan Pembangunan Manusia Berbasis Gender Menggunakan Bisecting K-Means,” Peran Penelit. Ilmu Dasar dalam Menunjang Pembang. Berkelanjutan, pp. 78-83, 2016, [Online]. Available: http://riset.fmipa.unpad.ac.id/proc_semnasmipa2016/017. 078 - 083 Dila Fitriani.pdf.

[22] D. A. Wicaksana, P. P. Adikara, and S. Adinugroho, "Clustering Dokumen Skripsi Dengan Menggunakan Hierarchical Agglomerative Clustering," J. Pengemb. Teknol. Inf. dan Ilmu Komput. Univ. Brawijaya, vol. 2, no. 12, 2018.

[23] D. Jollyta, S. Efendi, M. Zarlis, and H. Mawengkang, "Optimasi Cluster Pada Data Stunting: Teknik Evaluasi Cluster Sum of Square Error dan Davies Bouldin Index," Pros. Semin. Nas. Ris. Inf. Sci., vol. 1, no. September, p. 918, 2019, doi: 10.30645/senaris.v1i0.100.

[24] M. I. Komputer, F. I. Komputer, and U. D. Nuswantoro, "Algoritma Cluster Dinamik Untuk Optimasi Cluster Pada Algoritma K-Means Dalam Pemetaan Nasabah Potensial,” J. Intell. Syst., vol. 1, no. 1, pp. 33-36, 2015.

[25] F. Ramdhani and A. Hoyyi, "Pengelompokan Provinsi Di Indonesia Berdasarkan Karakteristik Kesejahteraan Rakyat Menggunakan Metode K-Means Cluster,” J. Gaussian, vol. 4, no. 4, pp. 875884, 2015. 